\title{
Quality of life goes beyond the medical priorities in multiple sclerosis: assessing the impact of social support network
}

\author{
A qualidade de vida vai além das prioridades médicas na esclerose múltipla: avaliando o \\ impacto da rede de suporte social
}

Douglas Kazutoshi Sato', Renata Brant de Souza ${ }^{1,2}$

${ }^{1}$ Pontifícia Universidade Católica do Rio Grande do Sul, Faculdade de

Medicina,Instituto do Cérebro do Rio Grande do Sul, Porto Alegre RS, Brasil;

2Santa Casa de Belo Horizonte,

Belo Horizonte MG, Brasil.

Correspondence: Douglas Kazutoshi Sato; Instituto do Cérebro do Rio Grande do Sul (InsCer) e Escola de Medicina da PUCRS; Av Ipiranga, 6690 / Prédio 63; 90610-000 Porto Alegre RS, Brasil; E-mail:douglas.sato@pucrs.br

Conflict of interest: There is no conflict of interest to declare.

Received 17 April 2017

Accepted 24 April 2017

\section{(cc) BY}

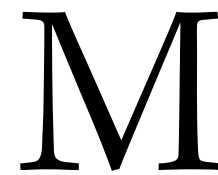

ultiple sclerosis (MS) is a chronic autoimmune demyelinating disease of the central nervous system (CNS)whose pathophysiologic mechanisms involve neuroinflammation and neurodegeneration ${ }^{1}$. MS potentially cause permanent disability that could impair quality of life (QoL) $)^{2,3}$. Neurologic deficits, fatigue and psychiatric manifestations ${ }^{4}$ could prevent social inclusion and cause economic burden ${ }^{5}$. However, there are many other determinants of QoL perception such as cultural standards, social conditions and coping skills'.

Social network provides social support and includes all people linked by social relationships, such as family, volunteer groups, sports and leisure meetings. A well-established Social Support Network (SSN) helps to improve the QoL as it provides emotional and financial support. SSN also ameliorates adherence to treatment and rehabilitation?

In this issue of Arquivos de Neuro-Psiquiatria, Costa et al. ${ }^{8}$ evaluated the relationship between the SSN and health related quality of life (HRQoL) in MS patients. They found a correlation between the SSN measured by the Medical Outcomes Study Social Support Survey and the HRQoL measured by the Short-Form Health Survey Questionnaire (SF-36) among 150 MS patients from Portugal. These results are similar to studies in other diseases, suggesting that the perception of HRQoL is influenced by the $\mathrm{SSN}^{9}$.

Despite the importance of mental health and social inclusion in HRQoL shown in this study, it is relatively common that physicians and patients have different perceptions and goals related to the disease and its management. For example, Kremenchutzky et al observed in 99 patients MS that physical functioning was the main goal for neurologists, while patients have strong expectations on retaining good mental health ${ }^{10}$. Moreover, physicians usually focus on the treatments and the disease monitoring, but patients' QoL is strongly influenced by social integration and ability to have a good performance at work.

Possa et al. ${ }^{11}$ recently evaluated the impact of the diagnosis of MS in QoL and found a relevant perception of change in health even in earlier phases of the disease and without association with EDSS score or time from diagnosis, with the same pattern of responses of patients with higher disability and disease duration. This suggests that self-perception and psychological wellbeing are affected early in the disease course, indicating thatwe should always seek patients' satisfaction asone of the top goals of medical care. In addition, we will probably improve long-term outcomes derived from patients' perceptions and facilitate adherence to treatments if we can include measures that help patients to improve their SSN since the initial phases of MS.

In the last few years, an increasing number of drugs have been approved for MS, including new oral drugs and monoclonal antibodies. All these drugs are effective on controlling MS relapses reducing CNS inflammation, but they still have a limited effect on neurodegenerative processes. Nevertheless, we can reduce the chance of permanent disability with optimal MS management in order to maintain physical and psychosocial functionality. Unfortunately, many MS patients experience high rates of unemployment despite the high level of education $^{5,12}$. SSN may help these patients to seek alternative social roles and life satisfaction, providing important support to maintain their QoL. 
1. Costa BK, Sato DK. Time to target brain atrophy and neurodegeneration in multiple sclerosis. Arq Neuropsiquiatr. 2016;74(3):181-2. https://doi.org/10.1590/0004-282X20160028

2. Morales RR, Morales NM, Rocha FC, Fenelon SB, Pinto RM, Silva $\mathrm{CH}$. [Health-related quality of life in multiple sclerosis]. Arq Neuropsiquiatr. 2007;65(2B):454-60. Portuguese. https://doi.org/10.1590/S0004-282X2007000300018

3. Costa DC, Sá MJ, Calheiros JM. The effect of social support on the quality of life of patients with multiple sclerosis. Arq Neuropsiquiatr. 2012;70(2):108-13. https://doi.org/10.1590/S0004-282X2012000200007

4. Murphy R, O'Donoghue S, Counihan T, McDonald C, Calabresi PA, Ahmed MA et al. Neuropsychiatric syndromes of multiple sclerosis. J Neurol Neurosurg Psychiatry. 2017; pii: jnnp-2016-315367. https://doi.org/10.1136/jnnp-2016-315367

5. Fragoso YD, Finkelsztejn A, Giacomo MC, Russo L, Cruz WS. The effect of multiple sclerosis on the professional life of a group of Brazilian patients. Arq Neuropsiquiatr. 2010;68(6):914-7. https://doi.org/10.1590/S0004-282X2010000600016

6. Study protocol for the World Health Organization project to develop a Quality of Life assessment instrument (WHOQOL). Qual Life Res. 1993;2(2):153-9. https://doi.org/10.1007/BF00435734
7. Heaney CA, Israel BA. Social networks and social support. 4th ed. Health Behavior and Health Education. 2002:185-209.

8. Costa DC, Sá MJ, Calheiros JM. Social support network and quality of life in multiple sclerosis patients. Arq Neuropsiquiatr. 2017;75(5):267-72. https://doi.org/10.1590/0004-282X20170036

9. Forouzan AS, Jorjoran Shushtari Z, Sajjadi H, Salimi Y, Dejman M. Social support network among people living with HIV/AIDS in Iran. AIDS Res Treat. 2013;2013:ID715381. https://doi.org/10.1155/2013/715381

10. Kremenchutzky M, Walt L. Perceptions of health status in multiple sclerosis patients and their doctors. Can J Neurol Sci. 2013;40(2):210-8. https://doi.org/10.1017/S0317167100013755

11. Possa MF, Minacapelli E, Canale S, Comi G, Martinelli V, Falautano M. The first year after diagnosis: psychological impact on people with multiple sclerosis. Psychol Health Med. 2017. https://doi.org/10.1080/13548506.2016.1274043

12. Moore P, Harding KE, Clarkson H, Pickersgill TP, Wardle M, Robertson NP. Demographic and clinical factors associated with changes in employment in multiple sclerosis. Mult Scler. 2013;19(12):1647-54. https://doi.org/10.1177/1352458513481396 